\title{
A smartphone microscopic method for rapid screening of cloth facemask fabrics during pandemics
}

\author{
Bhanu B Neupane ${ }^{\text {Corresp., } 1}$, Ravindra K Chaudhary ${ }^{2}$, Amita Sharma $^{3}$ \\ ${ }^{1}$ Central Department of Chemistry, Tribhuvan University, Kathamndu, Nepal \\ 2 Amrit Campus, Department of Chemistry, Tribhuvan University, Kathmandu, Nepal \\ ${ }^{3}$ Center for Analytical Sciences, Kathmandu Institute of Applied Sciences, Kathmandu, Nepal \\ Corresponding Author: Bhanu B Neupane \\ Email address: bbneupane@cdctu.edu.np
}

\section{Background:}

In pandemics, because of increased demand and subsequent shortage of commercial facemasks, people need to use cloth facemasks; although such masks are reported to provide reduced protection. These masks can be prepared in local levels from different fabric material. In developing countries, cloth masks are preferable because of low cost and added advantages of reusability. The filtering performance of a cloth facemask depends on the facial fit and on the material properties of fabrics such as porosity, yarn spacing or packing, and pore size. In resource limited settings, an affordable and easy to implement method that can assess the surface properties of cloth facemask fabrics would be important.

\section{Methods:}

In this work, we developed a smartphone microscopic method for rapid screening of fabric quality. We measured the field of view of the microscope and as a proof of concept, we implemented the method to examine surfaces of sixteen locally available cloth mask fabrics.

\section{Results:}

Out of the sixteen masks examined, we found very diverse yarn packing and pore morphology (pore size and shape) in the fabrics. The pore size ranged from 80 to 720 micrometer; much larger than respiratory droplet and bio-aerosol. This observation partly explains why such cloth facemask provide reduced protection to the user during pandemics. The performance of a cloth facemask partly depends on the material properties of fabric such as yarn packing, pore size, porosity. So, the surface properties of fabrics obtained from smartphone method can be used to get preliminary idea on the facemask quality. We believe that the method can be an affordable and rapid method for selection of better fabrics for cloth facemask during pandemics. 
1

2

3

4

5

6

7

8

9

10

11

12

13

14

15

16

17

18

19

20

21

22

23

24

25

26

27

28

29

30

31

32

33

34

35

36

37

38

39

40

41

42

43

44

45

46

47

\section{A smartphone microscopic method for rapid screening of cloth facemask fabrics during pandemics}

\section{*Corresponding author}

Bhanu Bhakta Neupane

Central Department of Chemistry, Tribhuvan University, Kathmandu Nepal

Emial address: bbneupane@cdctu.edu.np

1) Central Department of Chemistry, Tribhuvan University, Kathmandu Nepal

2) Center for Analytical Sciences, Kathmandu Institute of Applied Sciences, Kathmandu, Nepal

3) Department of Chemistry, Amrit Campus, Tribhuvan University, Kathmandu Nepal 
48

49

50

51

52

53

54

55

56

57

58

59

60

\section{ABSTRACT}

\section{Background:}

In pandemics, because of increased demand and subsequent shortage of commercial facemasks, people need to use cloth facemasks; although such masks are reported to provide reduced protection. These masks can be prepared in local levels from different fabric material. In developing countries, cloth masks are preferable because of low cost and added advantages of reusability. The filtering performance of a cloth facemask depends on the facial fit and on the material properties of fabrics such as porosity, yarn spacing or packing, and pore size. In resource limited settings, an affordable and easy to implement method that can assess the surface properties of cloth facemask fabrics would be important.

\section{Methods:}

In this work, we developed a smartphone microscopic method for rapid screening of fabric quality. We measured the field of view of the microscope and as a proof of concept, we implemented the method to examine surfaces of sixteen locally available cloth mask fabrics.

\section{Results:}

Out of the sixteen masks examined, we found very diverse yarn packing and pore morphology (pore size and shape) in the fabrics. The pore size ranged from $\sim 80$ to 720 micrometer; much larger than respiratory droplet and bio-aerosol. This observation partly explains why such cloth facemask provide reduced protection to the user during pandemics. The performance of a cloth facemask partly depends on the material properties of fabric such as yarn packing, pore size, porosity. So, the surface properties of fabrics obtained from smartphone method can be used to get preliminary idea on the facemask quality. We believe that the method can be an affordable and rapid method for selection of better fabrics for cloth facemask during pandemics. 


\section{Introduction}

Facemasks and respirators are the important component of personal protective equipments to contain the bio-aerosol and droplet mediated transmission of a disease. The filtering efficiency of a filtering device depends on nature of filter medium, size of particle, and environmental conditions (Barrett \& Rousseau, 1998; Hutten, 2015; Neupane \& Giri, 2020). The level of protection a filtering device provides also depends on the user compliance and the facial seal(Bard et al., 2019). To prevent the human-to-human transmission of a disease, for example COVID-19, a proper filtering device should be worn and other infection and prevention control measures should be followed. Also, special precaution should be followed while wearing and disposing the contaminated mask(Organization, 2020, p. 19). In resource limited settings and during outbreaks, because of increased demand and subsequent shortage of commercial masks(Ha, 2020), facemask made from locally available fabric material are also widely used. The cloth facemask are preferable due to low cost and added advantages of reusability and lower breathing resistance (Chughtai, Seale \& MacIntyre, 2013).

Studies on particulate matter filtering performance of two layered cloth facemasks have reported that such masks provide poor filtration efficacy to the user(van der Sande, Teunis \& Sabel, 2008; Rengasamy, Eimer \& Shaffer, 2010; Shakya et al., 2017). A study on aerosol filtering efficiency of common fabrics and their combination is reported in a recent study and recommended that fabrics having high yarn packing and low porosity along with multi-layered design is required for better performing cloth facemask(Konda et al., 2020). Study on virus filtering efficiency in laboratory settings is also reported in literature. The cloth facemasks, depending on the type of fabrics, is reported to have virus (bacteriophage MS2) filtering efficiency of 50-70\%(Davies et al., 2013). The virus filtering efficiency of three ply SMS (Spun bonded-Melt blown-Spun bonded) type surgical masks and N95 respirators was reported to be 85-95\%(Balazy et al., 2006; Davies et al., 2013)and 95-97\%(Balazy et al., 2006, p. 95; Harnish et al., 2016; Rengasamy et al., 2017; Zhou et al., 2018), respectively. A cluster randomized trial study on the effectiveness of cloth masks(Davies et al., 2013), medical masks(Leung et al., 2020) and respirators(Radonovich et al., 2016) in hospital settings are also reported. It was found that the influenza like illness was higher in health care personnel who wore cloth facemask than those who wore surgical facemask(MacIntyre \& Chughtai, 2015). This study suggested that cloth facemask cannot be recommended in hospitals settings. Nonetheless, in public places during pandemics, where social 
110 distancing is difficult to maintain and commercial masks are not available, it is recommended to

111 use cloth facemask(CDC, 2020).

112 The poor performance of cloth masks is due to improper facial fit and inherent properties of fabrics

113 used. If a fabric having high yarn or thread packing and low porosity (or high cover factor), for 114 example a tightly weaved cotton having 600 threads per inch, is used in designing a facemask then 115 user can get better filtration efficacy(Konda et al., 2020). The facemasks designed from fabrics 116 having high yarn packing and smaller pores (as low as $80 \mu \mathrm{m}$ ) perform better than masks designed 117 from fabrics having larger pores (Neupane et al., 2019). It means selection of proper fabrics is 118 important in designing a better performing cloth facemask. In pandemics and in resource limited 119 settings standard filtering efficiency measurement setup is difficult to access, so an affordable and 120 easy to implement method that can guide the mask user and or designer for selection of better 121 fabrics for cloth facemask would be important.

122 In this work, we developed a portable smartphone microscope system that can image the cloth 123 facemask fabrics in bright field mode. We measured the field of view of the microscope and 124 applied it to image the surface of sixteen two-layered cloth facemasks. The optical images were 125 analyzed to get information on yarn packing and pore size. A guideline for selection of better 126 fabrics for cloth facemask during pandemics is also provided.

127

\section{Materials and methods}

129 Design of microscope system

130 The spherical sapphire ball lens of $4 \mathrm{~mm}$ diameter was purchased from Edmond Optics, USA (unit 131 price $\sim \$ 20)$. An aluminum plate $(2 \times 2 \times 0.1 \mathrm{~cm})$ was obtained from a local machine shop and a hole 132 of $\sim 3.5 \mathrm{~mm}$ diameter was made at the center of the plate. The ball lens was fixed on the hole with 133 the help of transparent nail polish (figure 1A). The assembly was then mounted on the smartphone 134 camera $(3120 \times 4160$ pixels, screen size $12.2 \times 6.7 \mathrm{~cm})$ with the help of double sided transparent tape. 135 The working distance between smartphone camera and ball lens assembly was adjusted by 136 inserting a piece of a paper cardboard $(2 \times 2 \times 0.1 \mathrm{~cm})$ having a hole of around $0.8 \mathrm{~cm}$ diameter at the 137 center. The light source needed for illumination was made by putting a white LED in closed 138 cardboard box of $15 \times 15 \times 15 \mathrm{~cm}$ dimension that had a $0.5 \mathrm{~cm}$ hole (called illuminating hole) on the 
139 top center of the box. The whole assembly is called smartphone microscope. A simple schematics

140 of the microscope is shown in $1 \mathrm{~B}$.

141 To measure the field of view of the microscope, a calibration slide (figure 1C) having minimum

142 inter-grid distance of 10 micrometer was placed on the top of light box pinhole and imaged onto

143 the smartphone camera. The number of grids in the central focused region in the image were

144 counted to get the field of view in micrometer.

145 The field of view (FOV) of an imaging system is the maximum area that can be observed in a 146 camera or in an eyepiece(Stender et al., 2013). The FOV of a ball lens depends on its diameter, 147 refractive index of the lens material (n), and wavelength of light used $(\lambda)$. The FOV increases with 148 the increase of ball lens diameter. Theory predicts that the FOV for $4 \mathrm{~mm}$ sapphire ball lens $149(\mathrm{n}=1.77)$ at $\lambda$ of $0.55 \mu \mathrm{m}$ is around $740 \mu \mathrm{m}$ (Cybulski, Clements \& Prakash, 2014).

150 The spherical ball lens has curved surface. This result in curvature effect i.e. rays incident on the 151 lens surface are not focused at the same image plane. Because of this effect only the central region 152 of the image can be used for study. If balls lens is attached to the smartphone camera, the FOV is 153 also partly determined by smartphone camera specifications. The effective FOV of our smartphone 154 microscope system was $760 \pm 5 \mu \mathrm{m}$.

Imaging of face mask

157 Cloth face masks were purchased from local markets (unit price \$0.2-0.3). All masks had two layers having stretchable ear loops (figure 1D). The masks, however, had same or different fabrics in two layers. The masks having same and different fabrics in two layers are hereunder labeled as type I and II masks, respectively. A total of twelve type I (labeled M1-M12) and four type II (labeled M13-M16) masks were selected for the study. For each mask M1-M16, three replicas were considered. The information on the type of fabrics used in mask is provided in table 1 . The masks containing spandex were more stretchable than others. 
167 For imaging, a small piece of mask $(50 \mathrm{~mm} \times 10 \mathrm{~mm})$ was cut with scissors without stretching the 168 mask surface. The piece was placed flat on a clean glass slide. The slide was then placed on the 169 top of light box hole and imaged with the smartphone microscope. We did preliminary inspection 170 of all three replicas with the smartphones microscope and found their images similar. So, we saved 171 the image of only one of the replica and did further analysis. Around 5-10 images were collected 172 in the different regions of the mask for each layer by manually scanning the smartphone 173 microscope. The collected images were transferred to computer and imported to ImageJ software 174 (NIH, USA). The pixel number was converted to micrometer to get the pore size information. To 175 get the information on yarn packing we calculated the total cover factor of fabric $(f)$ i.e. the $\%$ of 176 total area of fabrics covered by yarns, which is defined as:

$$
f=\left(\frac{A_{\text {yarn }}}{A_{\text {total }}}\right) 100
$$

where, $A_{\text {yarn }}$ is total area covered by yarns in the fabric and $A_{\text {total }}$ is the total area covered by the fabric or total accessible area. The approximate cover factor was obtained from the microscopic images of the fabrics as (Tàpias, Ralló \& Escofet, 2011):

$$
f^{\prime}=\left(\frac{n_{\text {yarn }}}{n_{\text {total }}}\right) 100
$$

where, $n_{\text {yarn }}$ is total number of pixels corresponding to yarns and $n_{\text {total }}$ is the total number of pixels in the fabric image. Manual thresholding was used to classify the pixels as dark pixels (that correspond to yarn) and bright pixels (pores) in the ImageJ software. The opposite term of cover factor is porosity and was calculated as:

$$
\text { Porosity }=100-f^{\prime}
$$




\section{Results}

193

194

195

196

197

198

199

200

201

202

203

204

205

206

207

208

209

210

211

212

213

214

215

216

217

218

219

220

\section{Imaging the surface of type I masks}

The images of all the masks were collected in bright field mode, so the bright patches on the image represent the pores and the dark regions the yarns (Figure 2 and S1). The pores in the fabrics surface, except in the M6 and M12 masks, are clearly visible and mostly asymmetric. This creates a challenge to measure dimension of the pore. Nonetheless, we measured the longest dimension of the pores in the fabric to get the approximate upper estimate of the pore size. It is interesting to see the pores of diverse morphology, yarns of different diameter, and also the difference in yarn packing in the fabrics of different masks. The pores in M6 and M12 are not easily visible, but we adjusted the image contrast and measured the size of brightest region in the image to estimate of pore size. Since the pores are not obvious, the pore size estimation obtained from contrast adjustment in M6 and M12 masks may have more error.

To get quantitative information on yarn packing, we also calculated the $\%$ of total area covered by yarn (cover factor) for the fabrics in all the masks by using the methodology provided in experimental section (equation 2). The pore size and cover factor data for the fabrics in type I masks is provided in table 2 . It is interesting to see pore size in the range of $\sim 77$ (in M6) to $\sim 460$ $\mu \mathrm{m}$ (in M10); larger than the typical size of respiratory droplets $(5-100 \mu \mathrm{m})$. The cover factor ranged from $\sim 66$ (in M10) to $\sim 96 \%$ (in M12).

\section{Imaging the surface of type II masks}

The images of type II masks were also collected in bright field mode. The type II masks had different fabrics in two layers, so the difference in surface of fabrics in two layers is very obvious in the images shown in figure 3 and S2. The pores size in the layer I of M16 are not easily visible, but we adjusted the image contrast and measured the size of brightest region within the image to get a rough estimate of pore size. Again as in M6 and M12 masks, the pore size estimation obtained from contrast adjustment can have more error. The pore size and cover factor data for both fabrics layers (L1 and L2) in the type II masks is provided in table 3. It is interesting to find the pore size in layer II of M15 are as big as 720 micrometer and cover factor as low as 42\%. As in type I masks, pores in all fabrics layers of type II masks are larger than the typical size of respiratory droplets. 


\section{Discussions}

\section{Surface properties of fabrics}

224 The pore size for type I masks ranges from $\sim 80$ to 460 micrometer. This observation suggests that the pore size in all masks is larger than bio-aerosols $(\leq 5 \mu \mathrm{m})$ and in majority of masks the pores are even larger than respiratory droplets $(5-100 \mu \mathrm{m})$. If masks having highly porous fabrics are

227

228

229

230

231

232

233

234

235

236

237

238

239

240

241

242

243

244

245

246

247

248

249 used, then user will get reduced protection from the respiratory viruses. Recent studies have shown that the filtering efficiency of a cloth facemask has strong relation to the fabrics microstructures and suggested that fabrics having high yarn or thread packing, low porosity, and small pores can capture more particles(Neupane et al., 2019; Konda et al., 2020). In our case, among all the masks, the cotton fabrics mask M6 has smallest pore size of $\sim 77$ micrometer and high cover factor of $\sim 94 \%$ (porosity $\sim 6 \%$ ). On the basis of this one can say that, out of 12 type I masks, a tightly weaved cotton facemask having low porosity (M6) could provide best filtration efficacy. The other cotton mask M12 having pore size of $\sim 80$ micrometer and cover factor of $\sim 96 \%$ (porosity $\sim 4 \%$ ) could perform as good as M6. The polyster-spandex mask M10, having pore size of $\sim 460$ micrometer and cover factor of $\sim 66 \%$ (porosity $\sim 34 \%$ ), will be worst of all. As in type I masks, the pores in type II masks (table 3) are much bigger than the bio-aerosols and respiratory droplets.

It is not surprising to see different pores size and shape, yarn diameter, and cover factor even in a same fabrics type (for example M2, M6, M11, and M12). The surface microstructures in fabric depends on how the fabric is weaved or knitted. A tightly weaved or knitted fabric will have smaller pores and high cover factor (low porosity) than a loosely weaved or knitted fabric.

\section{Implications to the filtering performance of facemask}

An important question one could have at this point is: How the surface properties of fabrics can be used to screen the cloth facemask quality? Cloth facemask are made from knitted or woven fabrics having low surface charges than electret materials used in surgical facemask and respirators(Barrett \& Rousseau, 1998). So, the facial fit and fabric properties such as yarn packing and pore size on the fabrics are the key parameters that affect the filtering efficiency of a cloth facemask. If yarns are tightly packed then smaller pores are formed. Recent studies have shown 
250 that the cloth facemask designed from fabrics having smaller pores and high thread or yarn packing 251 can filter more particles(Neupane et al., 2019; Konda et al., 2020). It means, the information on 252 the yarn or thread packing and pore size can be indirectly used for the screening the cloth facemask 253 performance. In our case, the two layered cotton fabric masks M6 and M12 mask, having relatively 254 smaller pores and high yarn packing, is expected to perform better than other masks.

255

256

257

258

259

260

261

262

263

264

265

266

267

268

269

270

271

272

273

274

275

276

277

278

279

Let us say, in pandemics, someone wants to design facemask from locally available fabrics. In resource limited settings and in pandemics one may not have standard instrument to assess the quality of fabrics. In such case, the available fabric materials can be inspected for relative pore size and yarn packing using smartphone microscope demonstrated here. Although, we mounted the ball lens to the smartphone camera for image analysis, screening can also be done directly with eye in presence of room or day light. Due to small working distance of ball lens(Cybulski, Clements \& Prakash, 2014), eye should be virtually touching the ball lens surface to see the image. After inspection, the fabric having smallest pore size and highest yarn packing can be selected for mask design. Such fabric along with improved design for better facial fitting could provide better filtration efficacy to the user.

We demonstrated an affordable fabric selection based for a better performing cloth facemask. It is known than cloth facemask provide low breathing resistance to the user. However, it would be interesting to study the breathability test of the recommended facemask. It would also be interesting to make a systematic study on fabrics surface properties and the virus filtration efficacy of the masks.

\section{Conclusions}

To summarize, we developed a smartphone microsphere that can image the cloth facemask fabrics.

We examined the surface of sixteen different cloth facemask and found diverse yarn packing, yarn diameter, porosity, and pores size and shape in the fabrics. Interestingly, we found that the pore size in the fabrics in the size in the range of 80 to 720 micrometer; much larger than respiratory droplet and bio-aerosol. This partly explains why such cloth facemask provide reduced filtration efficacy to the user. We recommend a tightly weaved or knitted fabrics having low porosity for designing a better performing cloth facemask. We believe that the method demonstrated here can be an affordable and rapid method for selection of better fabrics for cloth facemask during pandemics. 
280

281

282

283

284

285

286

287

288

289

290

291

292

293

294

295

296

297

298

299

300

301

\section{References}

Balazy A, Toivola M, Adhikari A, Sivasubramani SK, Reponen T, Grinshpun SA. 2006. Do N95 respirators provide $95 \%$ protection level against airborne viruses, and how adequate are surgical masks? American journal of infection control 34:51-57.

Bard RL, Ijaz MK, Zhang JJ, Li Y, Bai C, Yang Y, Garcia WD, Creek J, Brook RD. 2019. Interventions to Reduce Personal Exposures to Air Pollution: A Primer for Health Care Providers. Global heart 14:47.

Barrett LW, Rousseau AD. 1998. Aerosol loading performance of electret filter media. American Industrial Hygiene Association Journal 59:532-539.

CDC. 2020.Coronavirus Disease 2019 (COVID-19). Available at https://www.cdc.gov/coronavirus/2019-ncov/prevent-getting-sick/cloth-face-cover.html (accessed April 7, 2020).

Chughtai AA, Seale H, MacIntyre CR. 2013. Use of cloth masks in the practice of infection control—evidence and policy gaps. Int J Infect Control 9:1-12.

Cybulski JS, Clements J, Prakash M. 2014. Foldscope: origami-based paper microscope. PloS one 9:e98781.

Davies A, Thompson K-A, Giri K, Kafatos G, Walker J, Bennett A. 2013. Testing the efficacy of homemade masks: would they protect in an influenza pandemic? Disaster medicine and public health preparedness 7:413-418.

Ha KO. 2020.Coronavirus Latest: Global Mask Shortage May Get Worse - Bloomberg. Available at https://www.bloomberg.com/news/articles/2020-03-10/the-global-maskshortage-may-be-about-to-get-much-worse (accessed May 3, 2020). 
302 Harnish DA, Heimbuch BK, Balzli C, Choe M, Lumley AE, Shaffer RE, Wander JD. 2016.

303 Capture of $0.1-\mu \mathrm{m}$ aerosol particles containing viable H1N1 influenza virus by N95

304

305

306

Hutten IM. 2015. Handbook of nonwoven filter media. Butterworth-Heinemann.

307

308

309

310

311

312

313

314

315

316

317

318

319

320

321

322

323

Konda A, Prakash A, Moss GA, Schmoldt M, Grant GD, Guha S. 2020. Aerosol Filtration Efficiency of Common Fabrics Used in Respiratory Cloth Masks. ACS Nano.

Leung NH, Chu DK, Shiu EY, Chan K-H, McDevitt JJ, Hau BJ, Yen H-L, Li Y, KM D, Ip JS. 2020. Respiratory Virus Shedding in Exhaled Breath and Efficacy of Face Masks. Nature methods. DOI: https://doi.org/10.1038/s41591-020-0843-2.

MacIntyre CR, Chughtai AA. 2015. Facemasks for the prevention of infection in healthcare and community settings. Bmj 350:h694.

Neupane B, Giri B. 2020. Current understanding on the Effectiveness of Face Masks and Respirators to Prevent the Spread of Respiratory Viruses. EngrXiv. DOI: 10.31224/osf.io/h3wgc.

Neupane BB, Mainali S, Sharma A, Giri B. 2019. Optical microscopic study of surface morphology and filtering efficiency of face masks. PeerJ 7:e7142.

Organization WH. 2020. Advice on the use of masks in the context of COVID-19: interim guidance, 6 April 2020. World Health Organization.

Radonovich LJ, Bessesen MT, Cummings DA, Eagan A, Gaydos C, Gibert C, Gorse GJ, Nyquist A-C, Reich NG, Rodrigues-Barradas M. 2016. The Respiratory Protection Effectiveness Clinical Trial (ResPECT): a cluster-randomized comparison of respirator and medical 
mask effectiveness against respiratory infections in healthcare personnel. BMC infectious diseases 16:243.

326

327

328

329

330

331

332

333

334

335

336

337

338

339

340

341

342

343

344

Rengasamy S, Eimer B, Shaffer RE. 2010. Simple respiratory protection-evaluation of the filtration performance of cloth masks and common fabric materials against 20-1000 nm size particles. Annals of occupational hygiene 54:789-798.

Rengasamy S, Shaffer R, Williams B, Smit S. 2017. A comparison of facemask and respirator filtration test methods. Journal of occupational and environmental hygiene 14:92-103.

van der Sande M, Teunis P, Sabel R. 2008. Professional and home-made face masks reduce exposure to respiratory infections among the general population. PLoS One 3:e2618.

Shakya KM, Noyes A, Kallin R, Peltier RE. 2017. Evaluating the efficacy of cloth facemasks in reducing particulate matter exposure. Journal of Exposure Science \& Environmental Epidemiology 27:352-357. DOI: 10.1038/jes.2016.42.

Stender AS, Marchuk K, Liu C, Sander S, Meyer MW, Smith EA, Neupane B, Wang G, Li J, Cheng J-X. 2013. Single cell optical imaging and spectroscopy. Chemical reviews 113:2469-2527.

Tàpias M, Ralló M, Escofet J. 2011. Automatic measurements of partial cover factors and yarn diameters in fabrics using image processing. Textile research journal 81:173-186.

Zhou SS, Lukula S, Chiossone C, Nims RW, Suchmann DB, Ijaz MK. 2018. Assessment of a respiratory face mask for capturing air pollutants and pathogens including human influenza and rhinoviruses. Journal of thoracic disease 10:2059. 


\section{Figure 1}

Components of a smartphone microscope

(A) A $4 \mathrm{~mm}$ spherical ball lens mounted on an aluminum plate. (B) Schematics of the optical setup of the smartphone microscope. (C) Photograph of a calibration slide. The inset is the smartphone microscope image of the specified region within the slide to show the linear grid pattern. (D) A representative image of a cloth facemask used in this study.

A

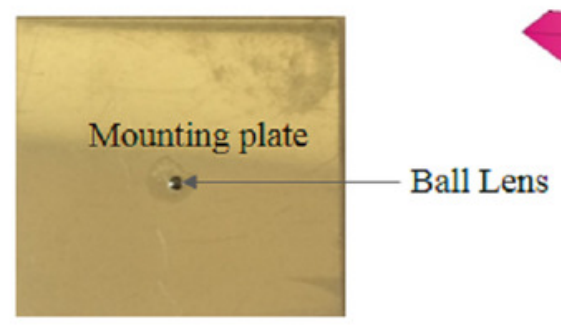

C

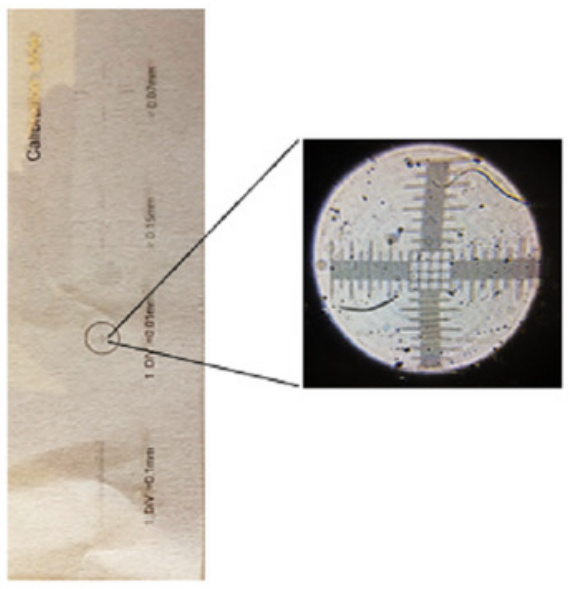

B

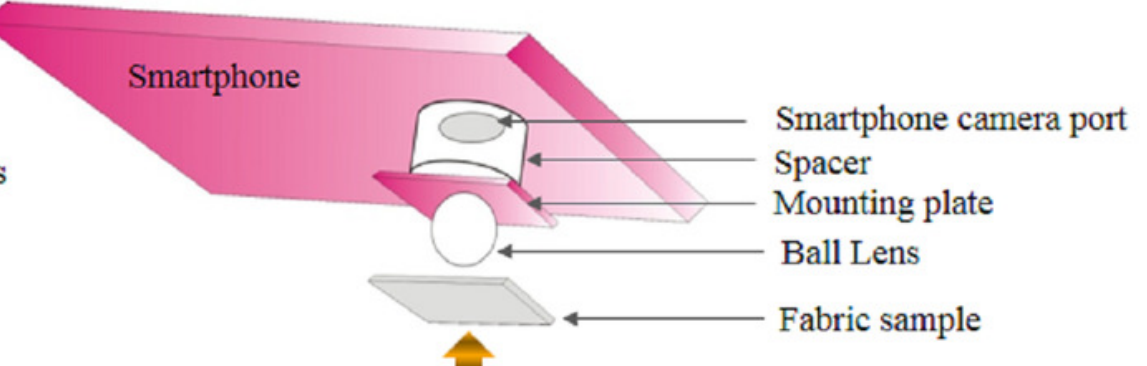

Light source

D

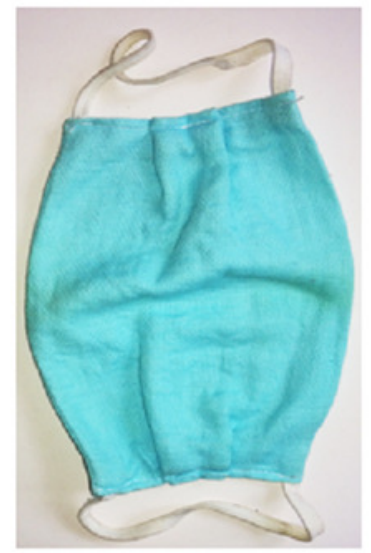


Figure 2

Representative images of some of the type I cloth facemask

(A) M1, (B) M2, (C) M5, (D) M6, (E) M10, and (F) M12. The scale bar shown in D is 400 micrometer and applies to all images. 

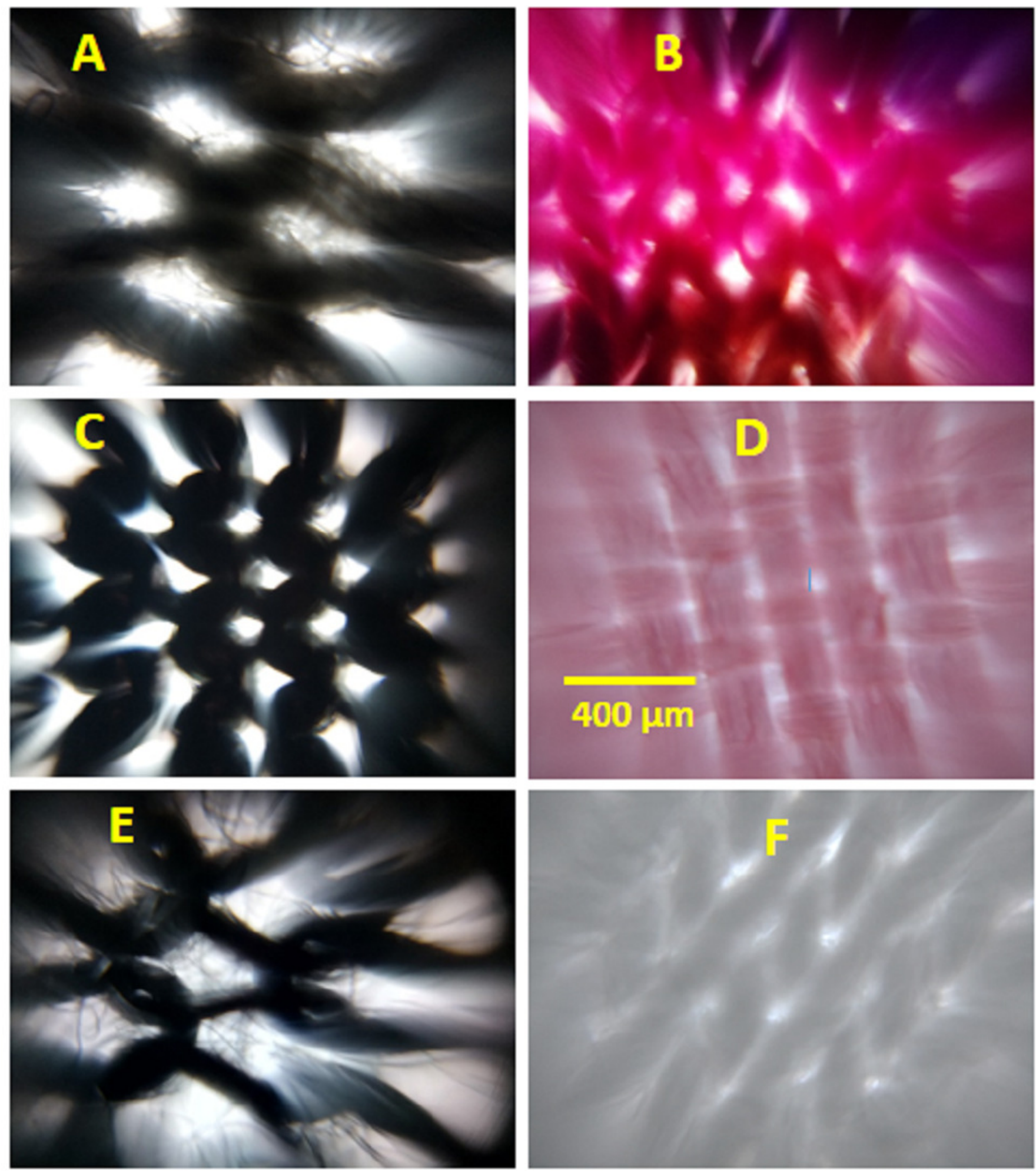
Figure 3

Representative images of type II face masks

(A) and (B) are the images of layer I and II for M13, (C) and (D) for M15, and (E) and (F) for M16, respectively. The scale bar shown in E is 400 micrometer and applies to all images. 

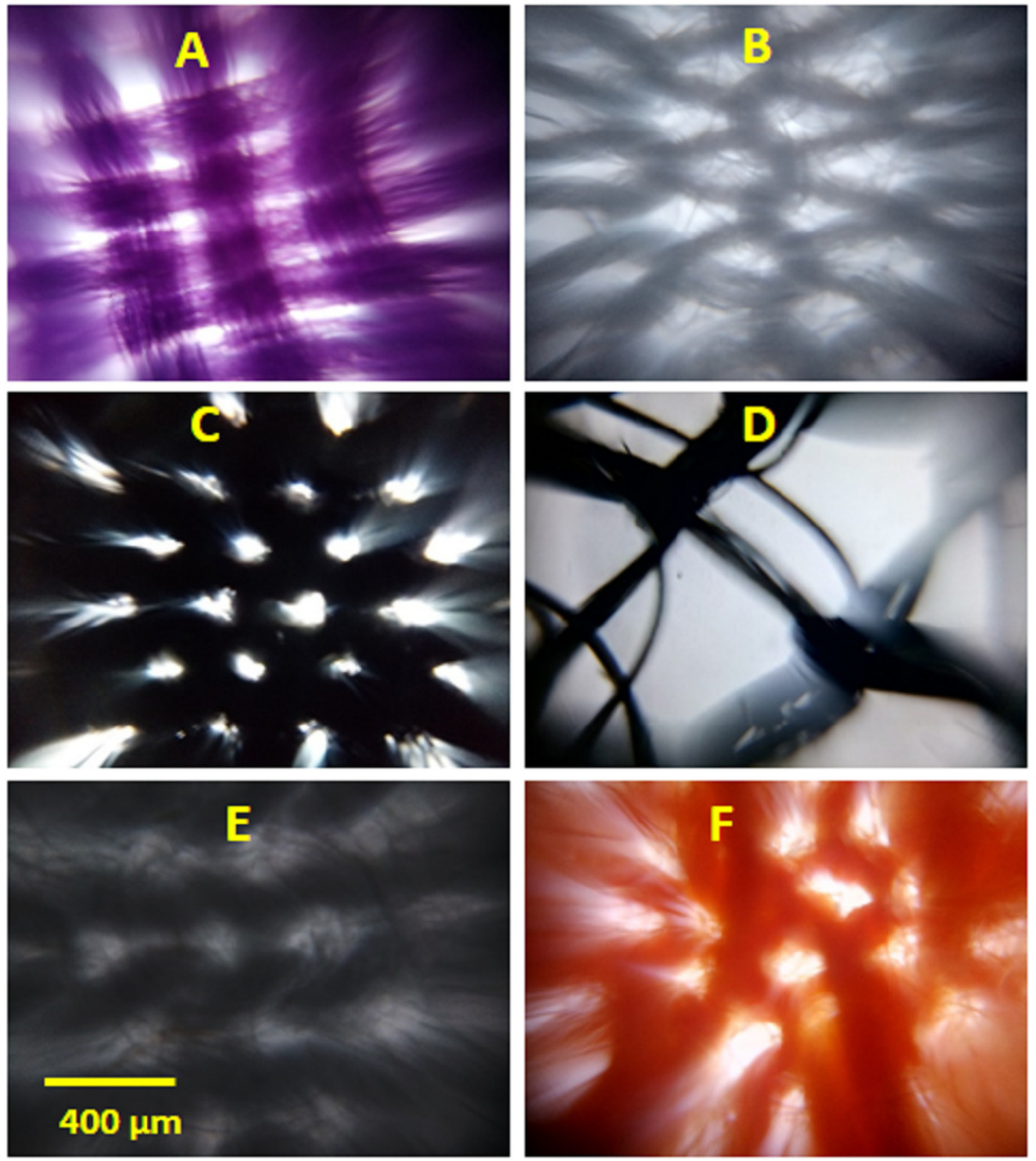


\section{Table 1 (on next page)}

Information on the cloth facemask fabrics.

L1 and L2 indicate the two fabric layers in type II masks. 
1

\begin{tabular}{|c|c|c|c|}
\hline Masks & Type of fabric & Masks & Type of fabric \\
\hline M1 & polyster-spandex & M9 & polsyter-spandex \\
\hline$M 2$ & cotton & M10 & polyster-spandex \\
\hline M3 & cotton-spandex & $M 11$ & cotton \\
\hline M4 & rayon-spandex & $M 12$ & cotton \\
\hline M5 & cotton-spandex & $M 13$ & cotton (L1) and polyster-spandex (L2) \\
\hline M6 & cotton & $M 14$ & polyster-spandex (L1) and rayon-spandex (L2) \\
\hline$M 7$ & cotton-spandex & M15 & cotton-spandex (L1) and polyster \\
\hline$M 8$ & cotton-polyster & M16 & cotton (L1) and cotton-spandex (L2) \\
\hline
\end{tabular}




\section{Table 2 (on next page)}

Pore size and cover factor in fabrics of type I masks

The mean pore size and cover factor was calculated form ten and five measurements, respectively. 
1

\begin{tabular}{c|ccccc} 
Masks & $\begin{array}{c}\text { Pore size } \\
(\text { mean } \pm \sigma) \mu m\end{array}$ & $\begin{array}{c}\text { Cover factor } \\
(\text { mean } \pm \sigma)\end{array}$ & Masks & $\begin{array}{c}\text { Pore size } \\
\text { (mean } \pm \sigma) \mu m\end{array}$ & $\begin{array}{c}\text { Cover factor } \\
\text { (mean } \pm \sigma)\end{array}$ \\
\hline M1 & $394 \pm 38$ & $78 \pm 4$ & $M 7$ & $204 \pm 23$ & $82 \pm 3$ \\
M2 & $167 \pm 26$ & $87 \pm 2$ & $M 8$ & $197 \pm 27$ & $87 \pm 1$ \\
M3 & $392 \pm 41$ & $79 \pm 2$ & M9 & $258 \pm 27$ & $83 \pm 2$ \\
M4 & $370 \pm 57$ & $72 \pm 9$ & M10 & $457 \pm 39$ & $66 \pm 4$ \\
M5 & $173 \pm 19$ & $88 \pm 2$ & $M 11$ & $138 \pm 15$ & $90 \pm 3$ \\
M6 & $77 \pm 8$ & $94 \pm 2$ & M12 & $80 \pm 9$ & $96 \pm 2$
\end{tabular}

2 


\section{Table 3(on next page)}

Pore size and cover factor in fabrics in layer I (L1) and layer II (L2) of type II masks

The mean pore size and cover factor was calculated form ten and five measurements, respectively. 
1

\begin{tabular}{c|cccc} 
Masks & $\begin{array}{c}\text { Layer I pore size } \\
\text { (mean } \pm \sigma) \mu m\end{array}$ & $\begin{array}{c}\text { Cover factor } \\
(\text { mean } \pm \sigma)\end{array}$ & $\begin{array}{c}\text { Layer II pore size } \\
\text { (mean } \pm \sigma) \mu m\end{array}$ & $\begin{array}{c}\text { Cover factor } \\
\text { (mean } \pm \sigma)\end{array}$ \\
\hline M13 & $187 \pm 14$ & $87 \pm 2$ & $336 \pm 21$ & $76 \pm 2$ \\
M14 & $245 \pm 15$ & $71 \pm 2$ & $374 \pm 19$ & $68 \pm 2$ \\
M15 & $172 \pm 16$ & $81 \pm 3$ & $723 \pm 20$ & $42 \pm 6$ \\
M16 & $216 \pm 15$ & $83 \pm 3$ & $179 \pm 38$ & $80 \pm 6$
\end{tabular}

2 